\title{
Imaginação, linguagem, espíritos e agência: ayahuasca e o tratamento da dependência química
}

DoI

http://dx.doi.org/10.11606/ 2179-0892.ra.2017.137322

\section{Marcelo S. Mercante}

- Sem instituição

$\checkmark$ marcelo_mercante@yahoo.com

\section{RESUMO}

Neste texto será analisado o papel das plantas utilizadas no tratamento da dependência química em uma comunidade terapêutica, Takiwasi, localizada na Amazônia peruana. Takiwasi tem na ayahuasca sua principal ferramenta no processo de recuperação de adictos. A ayahuasca é uma bebida psicoativa amplamente utilizada por diversos povos indígenas em toda a Amazônia e por três religiões brasileiras de base cristã. Em Takiwasi acredita-se que as plantas são dotadas de agência e possuem, além de seus princípios ativos, um outro tipo de ação mais desejada que a química: a espiritual. Para elucidar tal capacidade de agência e poder espiritual, utilizo as noções de "linguagem" de Benjamin e de "espírito" e "imagem" e "imaginação" de Viveiros de Castro. 
Neste texto busco evidenciar o papel das plantas utilizadas no tratamento da dependência em Takiwasi, uma comunidade terapêutica localizada na Amazônia peruana, onde realizei dois períodos de trabalho de campo (de 40 dias cada um) em setembro e outubro de 2009 e de 2010. Em Takiwasi acredita-se que as plantas são dotadas de agência e detêm, além de seus princípios ativos, um outro tipo de ação mais desejada que a química: a espiritual, que se desenvolve através da linguagem própria destas plantas. Tal linguagem se revela no processo de interação entre tais plantas e as pessoas que as consumiram, ação esta intermediada pelo ritual. Utilizarei aqui narrativas das experiências vividas por pacientes e terapeutas durante o uso destas plantas. Tais narrativas não devem ser vistas como "evidências" da "eficácia" deste tipo de tratamento, pois as pessoas entrevistadas estavam em pleno processo de tratamento: algumas foram bem-sucedidas, outras não. Tais narrativas devem antes de tudo ser encaradas como a base sobre a qual tal tratamento se desenvolve.

A planta que pode ser considerada como sendo a base do tratamento é a ayahuasca, um chá obtido pelo cozimento por longas horas de pedaços de um cipó (Banisteriopsis caapi) que contém beta-carbolinas e folhas de um arbusto (Psychotria viridis) que contém dimetiltriptamina (DMT). A interação de ambos os princípios ativos atua sobre o nível de serotonina no cérebro, produzindo diversas sensações, sendo a experiência de visões a mais marcante. A ayahuasca é amplamente utilizada por diversos grupos indígenas na Amazônia como um todo, não apenas no contexto da "cura" (central em Takiwasi), mas também em outras situações (ver Saez, 2014), assim como em três religiões de base cristã no Brasil, o Santo Daime, a Barquinha e a União do Vegetal (ver Labate e Araújo, 2002).

O uso tradicional de plantas (ou, no caso da ayahuasca, substâncias) psicoativas pela humanidade pressupõe a interação de humanos e não-humanos, seja o espírito da planta que se ingeriu, seja o espírito dos animais que se deseja caçar ou que estão causando doença, seja o espírito de (ou que habitam em) fenômenos naturais ou pontos geográficos específicos. Tais espíritos possuem agência, influenciando na vida dos seres humanos (ver Narby e Huxley, 2004), assim como possuem uma linguagem, através da qual se comunicam com os seres humanos. Muitos povos têm seus rituais apoiados no uso de uma ou mais destas plantas (ver Labate e Coulart, 2005), e o que se busca é um contato com os espíritos delas, tidos como seres muito sábios e poderosos ou mesmo, devido ao seu poder, perigosos. De qualquer forma, estes espíritos são "seres" capazes de transmitir, através de uma linguagem própria, informações e ensinamentos, realizar curas e malefícios.

Mais que isso, esses espíritos são capazes de revelar, através de sua linguagem, um universo normalmente invisível, de colocar quem experimenta tais plantas não só em contato com outros mundos, mas também com este mun- 
do nosso do dia a dia de uma forma totalmente distinta do "normal". Aqui, a própria noção de "psicoatividade" se expande: é fácil concluir que plantas como a ayahuasca, o peiote ou cogumelos são psicoativos, visto que produzem visões e estados de consciência bastante distintos do normal, do ordinário. Contudo, e as plantas de purga (ver adiante no texto), que são utilizadas simplesmente para produzir vômitos? Podem ser classificadas como "psicoativas"? Creio que sim, na medida em que, pelos relatos das próprias experiências adiante, veremos que junto com o que é vomitado saem a raiva, o rancor, emoções profundas e importantes, assim como a droga que se consumiu anos antes. Limpa-se, através da purga, não apenas o corpo físico, mas a mente e as emoções.

Aldous Huxley (1990) ao fazer experimentações com a mescalina (princípio ativo do peiote, cacto utilizado por diversos grupos indígenas norte-americanos), faz uma paráfrase de William Blake, e diz que tais substâncias são responsáveis por abrir as portas da consciência e da percepção. Após a abertura de tais portas, passa-se a ter a percepção de que o universo seria constituído por múltiplos níveis, alguns visíveis e outros não. Esta é uma noção que permeia as práticas xamânicas e cosmologias de diversos povos (ver Langdon, 1996). O que se encontra após tais portas estarem abertas pertence, exatamente, ao universo da linguagem espiritual destas plantas.

Segundo Shanon (2002), noesis e percepção estão tão intrinsecamente ligados durante os processos de miração (imagens mentais espontâneas que ocorrem durante o uso ritual da ayahuasca - ver Mercante, 2010, 2012 e 2013), que a linha entre conhecimento e percepção desaparece. Eu diria que tal linha divisória se dilui dentro de qualquer tipo de experiência causada pelo uso ritual de plantas/substâncias psicoativas. Não haveria como separar a interpretação de tudo mais que acontece durante a miração: "interpretação não é adicionada à percepção, mas está imbricada nesta" (Shanon, 2002: 110). Sendo assim, os significados oriundos de tais interpretações também estão imersos na experiência (o que não impede de posteriores reelaborações e reinterpretações por parte de quem passa por tais experiências). Huxley anota que, durante suas experiências com mescalina, houve momentos em que "as cores eram tão intensas, tão intrinsecamente significativas" (1990: 19) - as cores eram significados em si mesmas.

\section{O TRATAMENTO DA DEPENDÊNCIA}

Takiwasi é um centro terapêutico fundado pelo médico francês Jaques Mabit em 1992, na Amazônia peruana, na cidade de Tarapoto (Giove, 2000; Mabit, 2002 e 2007; Mabit et al., 1996; Mercante, 2013). Takiawasi está localizada em um local com alta incidência de uso de pasta de coca. Ciove (2000)' assinala que Tarapoto é o principal eixo comercial da região, e (em 2000) a maior produtora de folhas
1 Giove é Rosa Giove, esposa de Jacques Mabit, cofundadora de Takiwasi e médica deste centro. Rosa foi uma de minhas entrevistadas. Para que não haja confusão, quando me referir à "Giove", estou me referindo à Ciove (2000), seu livro. Quando estiver me referindo às narrativas colhidas nas entrevistas feitas por mim, utilizarei “Rosa”. O mesmo se dá com Jacques Mabit: "Mabit" se refere aos seus artigos, e "Jacques" às narrativas coletadas nas entrevistas feitas por mim. Jaques foi entrevistado em 25 de setembro de 2009 , tendo na época 54 anos. No Peru desde 1980, o médico e foi para este país por meio do Médicine Sin Frontiers. Rosa foi entrevistada em 19 de setembro de 2009 , sendo natural de Lima, Peru. 
de coca e pasta básica de cocaína do Peru, uma região de grandes contrastes sociais e econômicos.

Takiwasi atende um máximo de 15 pacientes por vez, apenas homens. Sua equipe terapêutica é formada por dois médicos (Jacques e Rosa), psicólogos, um padre cristão, um ergoterapeuta, além de eventuais curandeiros (que podem ou não ter origem indígena).

Este centro está voltado para a reabilitação de dependentes e, ainda que o aspecto central de seu tratamento seja o uso ritual da ayahuasca, há o emprego de diversas outras técnicas, tanto oriundas da medicina tradicional amazônica como o uso de dietas e "purgas" (uso de plantas para provocar vômitos), como o acompanhamento psicoterapêutico.

O tratamento é estruturado em três eixos: uso de plantas, psicoterapia e convivência. As plantas são agentes principais nas dietas, na ayahuasca, nas purgas. Elas são vistas como "seres espirituais" e seu papel no processo de tratamento dos pacientes se dá, na visão das pessoas em Takiwasi, não apenas pela sua "ação química", mas sim por serem tais plantas "seres inteligentes" que são introduzidos no corpo do paciente para que, junto com este, possam trabalhar no seu tratamento, através de uma linguagem própria. Harrington (2008: 11) argumenta que as plantas são vistas como capazes de convencer os pacientes da "severidade de seu problema com as drogas, iluminar as raízes emocionais deste problema, limpar energeticamente o corpo, clarear o sentido de valor dos pacientes e reconectar os pacientes com seus corpos" ${ }^{2}$.

A base do sistema de tratamento de Takiwasi é a "medicina tradicional amazônica", forma pela qual Giove se refere ao corpo de conhecimentos e práticas dos curandeiros locais. Neste sistema corpo, mente e espírito são unos:

Alcançamos as esferas mental-afetiva emocional-existencial atuando sobre 0 corpo e vice-versa. (...) é precisamente esta matéria, o corpo físico, o instrumento e sujeito da cura, que deve ser "limpo", depurado, cuidado para que se possa acessar os conteúdos psíquicos internos, biográficos, transpessoais ou existenciais que permitirão o processo curativo (2000: 12).

A "medicina tradicional" peruana é extremamente complexa, e inclui, na visão da própria Giove, o que pode ser chamada de "medicina tradicional costeira" (praticada na costa do Peru), "andina" e finalmente "amazônica", e não se restringe, de modo absoluto, às práticas tradicionais indígenas. O próprio vegetalismo (atividade de curandeirismo peruana que funde crenças e práticas de origem indígena e cristã - ver Luna, 1986) pode ser considerado como uma das formas de manifestação da "medicina tradicional peruana". De fato, a base do tratamento é a medicina tradicional amazônica. Isso não quer dizer que Takiwasi se classifi-
2 Todas as traduções de citações de artigos e de entrevistas, tanto do espanhol quanto do inglês, foram feitas por mim. 
que como um centro (exclusivamente) de medicina tradicional amazônica.

Segundo Rosa:

A medicina [tradicional] amazônica tem um conhecimento muito fino a nível energético. Quando um curandeiro invoca o espírito de determinadas plantas é como se o espirito desta planta, sua característica, tivesse sido de algum modo extraída, em uma presença invisível, e pode ser transferida ao paciente para estruturá-los. Em pacientes que são muito "retorcidos", não só fisicamente, mas psicologicamente, quase sempre se chamam os espíritos de árvores que são muito altas, retas, para que esta energia, desta árvore, forme parte do corpo da pessoa e lhe dê esta característica. Vemos como não existindo uma diferenciação clara entre o que é biológico ou físico e o que é energético ou espiritual, o que é emocional, são corpos que interagem, ao mesmo tempo, em diferentes planos.

As purgas antecedem o ritual com ayahuasca (se acontece uma sessão de ayahuasca na sexta-feira, por exemplo, na quinta se faz uma purga). As pessoas que participaram do ritual de purga se dirigem a uma maloca específica (distinta da maloca onde se bebe ayahuasca), por volta das 15h. Lá encontram pequenos bancos baixos e baldes, dispostos em roda. Ao centro da maloca há uma mesa (sobre a qual são arrumadas as poções de purga) e uma cadeira, onde o curandeiro que dirigirá o ritual se senta. O curandeiro serve as doses de plantas purgativas para as pessoas. Todas as doses de plantas, assim como as pessoas presentes, são sopradas com tabaco (o curandeiro sopra sobre a cabeça, peito e mãos de cada paciente a fumaça de um "mapacho" - cigarro de tabaco forte). Em seguida o curandeiro começa a cantar os ícaros (sobre ícaros, ver Bustos, 2008), e aos poucos as pessoas começam a vomitar. Diversas plantas são utilizadas, e cada uma possui características próprias, sendo administradas de acordo com o momento que cada paciente se encontra no processo terapêutico. Por volta das 17h30, a sessão é encerrada e é recomendado que as pessoas fiquem em jejum até a manhã seguinte. É importante frisar que as purgas podem ser tomadas fora de um ritual em grupo, sempre que um paciente sente necessidade desta intervenção. É bastante comum pacientes pedirem purgas sempre que se sentem agitados, ansiosos, ou portando "energias negativas".

As dietas são períodos de isolamento, acompanhados da utilização de plantas. As pessoas ficam em um pequeno "tambo" - casa simples, de madeira, aberta em uma das paredes, onde se encontra apenas uma cama e um mosquiteiro - por oito dias. A dieta se inicia sempre em um sábado. Há a ingestão de plantas, cada uma com suas propriedades terapêuticas específicas. As pessoas que irão "dietar" se dirigem para a chácara de Takiwasi (localizada há 4km do centro de tratamento, no meio da floresta) na sexta, participam de uma sessão
3 De uma forma geral, quem dirige uma sessãoseja de ayahuasca, purga, ou mesmo uma dieta-é denominado "curandeiro" em Takiwasi. De forma cíclica, apenas pessoas com formação de curandeiros (adquirida através de um aprendizado longo com outro curandeiro) podem dirigir sessões. Jacques teve tal formação. Rosa, contudo, mesmo cantando nas sessões, não se considera curandeira, pois não passou por tal processo. 
de ayahuasca nesta noite, e quando esta termina, já na madrugada de sábado, a dieta propriamente dita tem início. É permitido que cada participante coma um pouco de arroz por dia, acompanhado de duas bananas verdes: há uma restrição alimentar severa durante a dieta, sendo vedado o consumo de sal e açúcar. A restrição de açúcar se estende ainda por mais quinze dias após o período de isolamento. A dieta termina no sábado seguinte com a ingestão de sal, servido em uma salada na qual há cebolas, limão e salsa. A dieta é um período de purificação profunda, em que os sonhos se tornam extremamente intensos. Tais sonhos são trabalhados posteriormente, em sessões de psicoterapia específicas. Deve-se evitar também os odores fortes e relações sexuais.

Um aspecto fundamental de todo processo terapêutico de Takiwasi, também oriundo da medicina tradicional amazônica, é o uso de ícaros. Ícaros são músicas (que podem ou não ter letra-em qechua, espanhol ou mesmo outra língua - passando por assovios a onomatopeias, além de vocalizações sonoras). Saldaña e Guirrimán afirmam que tais "melodias mágicas" têm funções variadas, sendo um "elemento de apoio, para curar ou para fazer daño (...) é o veículo da energia pessoal do curandeiro, que engloba todo seu conhecimento (...) a quantidade e a eficácia dos ícaros são a expressão da sua constância no trabalho pessoal, seu conhecimento e poder" (2008: 17-18). Os ícaros são dados ao curandeiro pelos espíritos, e são a manifestação deste espírito, e podem ser passados pelos maestros aos seus aprendizes. Bustos adiciona que os ícaros são responsáveis por "influenciar, estruturar e promover a continuidade e o fluxo do estado de transe, afetando assim a qualidade e o conteúdo da experiência" (2008: 3).

Os terapeutas em Takiwasi também participam das "tomas" (ingestão) de plantas, ou seja, participam das purgas, das sessões de ayahuasca e das dietas. Este processo segue a lógica que todo psicólogo clínico deve também fazer sessões com outros psicólogos. Uma vez que em Takiwasi as plantas têm agência-eu poderia dizer que são parte mesmo da equipe terapêutica-, nada mais correto que os próprios psicólogos passarem por este processo.

Segundo Jacques, os terapeutas devem tomar plantas porque os pacientes tomam, para poder entender de fato a experiências pelas quais estes estão passando:

Ainda que você seja um bom psicólogo, entenda perfeitamente como se instalam traumas, como se instalam necessidades de substitutos, como é o desenvolvimento psicossexual e psicoemocional, ainda que você entenda tudo isso, ainda que você entenda de que necessita o paciente, se você não tem uma experiência de como trabal ham estas plantas, como você vai entrar em ressonância como que está se passando com o paciente? Você não entende bem o que se passa, você até pode entender intelectualmente, vocêse conecta com os esquemas que você 
aprendeu na tua formação como psicólogo. Através do uso de plantas, o terapeuta entra em outra ressonância, pode reagir a nível corporal, e das mensagens não-verbais. Ele vai trabalhar com o paciente em um nivel que, se ele não tiver tido a experiência com as plantas, ele não conseguiria. É uma forma de autoterapia. Para o terapeuta, é muito útil, pois se trabalha sobre o próprio corpo, e através disso ele [o terapeuta] se transforma. A base com que trabalha o terapeuta é sua personalidade, sua presença, isso atua mais que as palavras na terapia. As palavras são importantes, mas a comunicação vai além, você está presente com sua energia, você emana algo. Se você trabalha com as plantas sobre ti, você cresce como ser.

Isso fica evidente, por exemplo, nos relatos que se seguem. Julia ${ }^{4}$ era a única mulher trabalhando em Takiwasi como terapeuta. Segundo ela:

É impossivel, aqui, ser terapeuta sem tomar plantas. O trabalho com as plantas é fundamental. Creio que não posso me imaginar sem tomar plantas. Na minh a primeira ayahuasca, tive uma sensação de pertencimento com os pacientes, com seu cheiro. Na minha primeira sessão de ayahuasca, eu pude sentirsua dor, seu sofrimento, e o sentimento genuíno que devia fazer algo por isso. Por outro lado, também não conheço nenhum terapeuta que não tenha passado por isso. Todos quando tomam plantas com os pacientes percebem coisas dos seus pacientes nas suas sessões. Não digo grandes visões nem nada, mas sim uma comunicação em outro nível. Tem muitos que vomitam por seus pacientes, literalmente. A ayahuasca que guia e te ajuda a sentir os pontos críticos, as cores do outro. Os sonhos também. Um terapeuta pode ver seu paciente de outra maneira na sessão. Há uma troca de informações sobre os pacientes em outro nível.

Segundo Hans ${ }^{5}$, terapeuta em Takiwasi e de origem alemã:

Cada planta tem suas particularidades e atua em uma determinada direção. Além desta intenção geral, emocional, psicológica. E a planta te leva em uma determinada direção. Plantas são seres fisiológicos, são ingredientes bioquímicos, parte do ambiente, que entram em ressonância em determinadas partes das pessoas. Plantas diferentes atuam em partes diferentes do corpo, e trazem informações sobre o processo terapêutico.

Já havia mais de três anos que Hans estava trabalhando em Takiwasi, e ele teve uma experiência com "palos" durante uma dieta que lhe pareceu bem significativa e inesperada:
4 Excetuando-se Rosa Giove, Jacques Mabit e Jaime Torres, todos os outros participantes apresentados ao longo do texto-terapeutas e pacientes - receberam pseudônimos. Julia foi entrevistada em 06 de setembro de 2010. É natural de Santiago, Chile, e psicóloga, formada em 2008.

5 Entrevistado em 17 de setembro de 2010 , então com 35 anos. Natural de Berlim, Alemanha, era psicólogo havia cinco anos.

$6 \quad$ Palos é uma decocção tomada durante as dietas e feita a partir do cozimento da casca de várias árvores. Em comum, todas elas possuem a característica de serem altas e retas, o que conferiria a quem a toma tal "retidão" estrutural, seja psicologicamente, seja fisicamente. Os palos atuariam, segundo Jacques, no "eixo" da pessoa que toma tal beberagem. 
Depois de três anos tomando plantas eu estava esperando uma outra coisa. Eu me vi outra vez trabal hando sobre um ponto psicológico, de uma forma não esperada. Palos trabalham fortalecendo seu núcleo, e para isso, por vezes, é preciso trabalhar sobre as coisas que você não está vendo, sobre as coisas obscuras, a sombra: inveja, orgulho, coisas que vemos nos outros, mas não vemos em nós mesmo. Para atuar como terapeuta é preciso ter uma base firme, e é preciso integrar estas coisas. Depois de três anos, eu já me sentia melhor, e esta dieta me surpreendeu. A sessão de ayahuasca me surpreendeu, pois surgiram temas como desconfiança, e na dieta tive sonhos que não eram muito claros, mas todos faziam referência à integração de partes minhas que eu não queria ver. Isso foi, para mim, não exatamente desagradável, mas muito importante. Tive uma ideia da raiz de onde vinha tudo isso, e vi também nos sonhos referências ao tema de tornar consciente estas partes obscuras.

As condições de trabalho impõem ao terapeuta uma determinada postura que muitas vezes faz com que eles deixem de lado seus próprios problemas. A toma de plantas os puxa de volta para o trabalho psicológico sobre si mesmo, os faz ter consciência do quanto este trabalho sobre si mesmo é importante para sustentar o trabalho com os pacientes. Jaime Torres, diretor de Takiwasi, conta que em sua última dieta, quatro anos antes da entrevista que realizamos, ele teve a chance de "remover uma dor, uma tristeza. No dia a dia, os problemas, a gente supera, trata com a cabeça, mas na dieta isso não funciona. Começou a chover e eu comecei a chorar, chorar, a lavar, lavar, limpar".

\section{AYAHUASCA}

Jean7 , paciente em Takiwasi, só sentiu os efeitos do chá depois da segunda dose de ayahuasca, em sua primeira cerimônia. Mas, depois da segunda, "comecei a ter visões, foi horrível. A ayahuasca começou a me mostrar as coisas que eu devia trabalhar pessoalmente, sobre minha infestação, meus demônios, vi todos eles, tive muito medo, sentia calor, depois frio. Tentei sair da maloca, foram me buscar". Contudo, em um dado momento, Jean relata que "depois que fechei os olhos, vi que os demônios não estavam fora, mas dentro de mim. Sentia medo, e quando abri de novo os olhos eu era o demônio, era como se tivesse duas pessoas dentro de meu corpo".

Contudo, ao contrário do se poderia esperar, essa experiência não gerou um trauma, mas um entendimento profundo de sua própria situação. Para Jean:

Ver os demônios foi importante porque me dei conta que ao longo do caminho há muitas portas, e a ayahuasca vai abrindo as portas, mas cada porta que você
7 Entrevistado em 22 de setembro de 2009, 27 anos. Francês, não completou o segundo grau e estava há oito meses internado. 
abre já foi preparada pela ayahuasca, ela sabe tudo sobre o caminho, não há casualidade. A ayahuasca mostra as coisas da sua maneira, é uma planta muito inteligente. Se ela me mostrou estes demônios primeiro era porque estas eram as coisas mais importantes para serem trabalhadas. Me dei conta depois que tinham coisas dentro de mim, maneiras de pensar, coisa que a ayahuasca havia me mostrado a gravidade, e eu pensava que eu era forte.

Mateus ${ }^{8}$, também paciente em Takiwasi, me explicou que "nas sessões de ayahuasca você se confronta com o que tens que mudar na tua vida. As coisas em que você está errado". Em sua primeira sessão de ayahuasca, a mensagem que ele sentiu receber da planta foi: "limpeza, limpa-te". E, mais que algo "metafórico", essa era uma mensagem literal-ele sentiu necessidade de limpar o nariz muitas vezes. Além disso, ele

tinha sensação de ter pedras na boca. Tinha a sensação de estar banhado em fezes e urina humana, uma série de sensações corporais, e eu passava a sessão limpando meu corpo, e me dei conta que isso correspondia a uma necessidade de limpeza física da droga. Isso que comecei a sentir, que as drogas estavam me envenenando.

Passada esta primeira fase, Mateus mergulhou em um universo mais psicológico, como ele mesmo classificou suas experiências. Ele se deparou com "coisas que eu havia feito para minha família, que eu estava mal". Ele também teve que enfrentar a ideia da morte: "eu tinha uma atitude muito prepotente frente a morte, eu dizia que isso não me interessava, que eu iria viver minha vida e não tinha medo da morte, e a ayahuasca me fez enfrentar isso".

Para ele, as sessões de ayahuasca são importantes na medida em que elas ajudam a

[pôr] para fora teus temas, coisas que você não quer ver, que você não quer escutar, e ela te põe isso presente. Ela diz: "olha, esses são teus problemas, esse é você, soluciona teus problemas, lida com eles". E isso é muito importante. Em uma sessão de ayahuasca você pode ter informação suficiente para falar com 0 psicólogo por meses. Eu posso fazer psicoterapia por mais cinco anos e não vou conseguir avançar tanto quanto em uma sessão de ayahuasca. A forma que ela te mostra as coisas, ela te faz entender a urgência de lidar com o problema, que as consequências de não lidar com os problemas são sérias.

Jaime Torres", diretor de Takiwasi, passou por uma experiência muito "libertadora" em sua primeira sessão. Conta ele:
8 Entrevistado em 08 de setembro de 2009, com 28 anos. Natural de Lima, Peru, estudou administração de empresas. Cursou engenharia industrial por dois anos, mas não terminou. Viveu na Austrália por quase dois anos. Quando realizamos a entrevista, estava internado há 5 meses, e contou-me que usava cocaína desde os 18 anos.

9 Entrevistado em 11 de setembro de 2009, então com 38 anos. Natural de lquitos, Peru, e psicólogo. Trabalhara antes em dois hospitais, em alas de pacientes mentais, fazendo testes psicológicos, e participou em psicoterapia de grupo, mas foram trabalhos curtos. Já havia se formado há 17 anos, tendo estudado em Lima. Estava em Takiwasi desde 1994. 
Foi uma experiência muito curativa, psicoterapeuticamente muito profunda. Vi toda minha história antes de chegar a Takiwasi. Evivi momentos que me deixaram muito pesado emocionalmente, e sentia que me liberava. Em princípio estava muito perturbado, sem entender o que estava se passando. Eu vomitava e pensava que ia passar. Mas eu vomitava e a experiência aumentava! Depois disso o medo baixou um pouco, e tive essa experiência curativa, liberando todas as cargas. Estava tudo muito vinculado à depressão, a tristezas, eu chorava, chorava. Depois foi baixando, o curandeiro começou a trabal har em mim, e pouco a pouco fui sentindo que baixava, fui sentindo que estava mais estruturado, mais consciente. Foi muito intenso, mas depois foi mais sereno, mais harmonizado. Essa experiência me marcou muito.

Para ele houve uma "catarse, mas uma catarse total: física, mental e emocional. Em psicanálise um paciente às vezes chora, mas não acontece nada no corpo. Há um nível de liberação, porque a emoção flui, mas não é tão profunda quanto a ayahuasca".

Em 1986, Jacques passou por sua primeira experiência com ayahuasca, em Tarapoto, com um curandeiro local. Quando ele começou a sentir os efeitos da planta, ficou assustado:

Era tudo muito diferente, coisas que eu nunca havia sentido, energias, me assustei. E eu estava tão assustado que resisti, me bloqueei, para não entrar, por medo. Quando terminou a sessão, todos tranquilos e felizes, eu me senti um idiota, pois não havia acontecido nada comigo. Me dei conta que todos estavam bem.

Ele retornou dali a dois dias para outra sessão. Dessa vez, não teve tempo de racionalizar nada, ou de ter medo: "a mareação [o efeito da bebida] entrou de frente, e foi fortíssimo". Jacques sentiu que estava morrendo, e pensou "sou louco, porque estou tomando isso, com gente de outra cultura, isso é um veneno, um tóxico". Havia um combate se travando em seu interior. Do lado de fora ele não aparentava o que acontecia de verdade:

Por dentro, estava em um inferno. Até que entre os dois sentimentos, vida ou morte, eu aceitei morrer. Eentendi que não podia fazer nada, aceitei isso, e me dei conta que não tinh a muita importância, que não ia mudar nada no mundo por isso, em Tarapoto, nas pessoas, que eu era uma pessoa a mais no mundo, e que meu desaparecimento ia afetar minha família, mas que eu não tinha uma importância real. Isso foi muito forte, eu estava absolutamente certo que estava morrendo. No momento em que aceitei isso, "Jacques não tem importância"o combate terminou, a sensação de guerra interna desapareceu, de forma instantânea, através da aceitação. 
Ele passou a entender então que

toda a minha importância, meu ego, a importância que eu me dava a mim mesmo, que eu era importante para mim, mas para o mundo não. Isso foi na minha primeira sessão, e pouco a pouco eu voltava à normalidade, e à medida que voltava eu integrava o sentido. No dia seguinte, eu disse: "nunca mais vou tomar essa ayahuasca!" No dia seguinte eu comecei a entender tantas coisas, que eu não nunca havia entendido em 30 anos de vida eu havia entendido em uma noite. Me dei conta do seu potencial curativo que os ocidentais não podiam suspeitar.

No dia 25 de setembro de 2009, uma sexta-feira, participei de uma sessão em Takiwasi. Passei o dia todo de jejum, preparando-me. Antes de cada sessão é pedido que todos que vão participar tomem um banho de ervas que se encontra em um balde grande, no banheiro em frente à maloca. Curiosamente, antes de me banhar, encontrei Geraldo ${ }^{10}$, um paciente, conversando com uma espanhola que estava visitando Takiwasi e iria participar da sessão. Para minha surpresa, ele estava falando de sua família: dizia que havia sido separado de seus pais biológicos com menos de um ano de idade. Disse que sempre soube que era adotado, e que vivia com uma família de brasileiros, na Bolívia. Com 15, 16 anos resolveu ir em busca de sua família de nascimento, e começou a rodar pelo Peru. Finalmente, encontrou-os em Tarapoto. Descobriu que tinha um irmão gêmeo, e finalmente se reintegrou à sua família de origem. Esse relato me surpreendeu muito, pois, na entrevista que eu havia feito com ele, ele não havia mencionado nada disso.

Os efeitos da ayahuasca foram fortes logo de início, mais no estômago, não tive visões. Por fim, Jacques convidou para a segunda "toma". As pessoas começaram a se mover em direção a ele. Ao mesmo tempo, alguém do outro lado da maloca passava mal, vomitando e se engasgando. Antes de servir a primeira pessoa, Jacques foi ajudar esse que estava em uma passagem difícil. Tal pessoa era Ceraldo. Estava chorando muito e estava engasgado. Era nítido que não estava respirando direito. A situação foi se intensificando, ao ponto de finalmente as luzes serem acesas. Entre engasgos e golfadas contraídas de vômito, Geraldo balbuciava que não conseguia respirar (o que era evidente), mas também que seu pai-recém falecido, e que Geraldo não comparecera ao enterro, por decisão sua, para não interromper o tratamento - estava junto dele, e estava querendo levá-lo embora.

Ceraldo estava apavorado, primeiro por não poder respirar, segundo pela ameaça que sentia sofrer. Jacques, Jaime e Rosa se acercaram de Ceraldo, alternando-se em mantê-lo acordado, e auxiliando-o a respirar. Por vezes, a respiração voltava ao normal, mas depois se tornava dificultosa. Por fim, Jacques
10 Entrevistado em 22 de setembro de 2009. 23 anos. Natrual de Chiclayo, Peru. Acabara o Ensino Médio e cursava o segundo ano de engenharia civil em Tarapoto, onde viva já havia 12 anos. 
resolveu interromper a sessão, e não houve segunda toma. Auxiliaram Geraldo a caminhar, foram para o banheiro. Demoraram-se por lá. Finalmente voltaram, e Geraldo parecia um pouco melhor. Deitou-se. Novo desconforto. Ao retornar do banheiro ele foi deixado sozinho por uns minutos, e caminhava como um bêbado dentro da maloca, mal se sustentando pelas pernas.

Finalmente o levaram embora, para a Quadra, onde ficava o quarto dos pacientes. Não sei o que se passou, mas sei que foi preparada uma sopa para que ele tomasse. Jacques o levou para sua casa. Pela manhã, retornou sozinho à Takiwasi, e mais uma vez passou mal. Jacques o levou novamente à sua casa. Finalmente, às 16 hoo voltaram, e Ceraldo me pareceu bem.

O mais interessante foi que, quando contei a Tiago, terapeuta de Ceraldo sobre a suposta separação de Ceraldo de sua família, Tiago negou que isso tivesse acontecido realmente. Contudo, a alegada "mentira" se encaixa no processo de transformação de Ceraldo. Na entrevista ele havia falado de sua família, do quanto ele era importante para que esta se mantivesse unida, e da morte de seu pai. Na entrada do banheiro, uma nova imagem surgiu em cena, a da criança que fora abandonada, mas que por esforço próprio reencontrou sua família. Finalmente, na sessão, todo esse drama surgiu com força, na imagem do pai que vinha buscá-lo. Isso provavelmente gerou uma carga emocional extremamente intensa, que o sufocou, literalmente.

Fiz nova entrevista com Ceraldo, que me contou sobre a experiência:

A sessão de aya huasca foi forte... foi uma parte triste que tenho dentro de mim, eu a estava guardando, e a ayahuasca buscou um espaço para trazer isso para fora. Me agarrou muito forte. Eu estava pensando em meu pai, e a ayahuasca disse: "por aqui vamos começar". Comecei a me sentir mal, meu corpo estava no outro mundo, a maior parte da minha alma estava no outro mundo. Aí comecei a tossir, engasgar. Eu pensava em meu pai e via uma coisa branca, via um caminho e quatro anéis. Aí comecei a tossir. Me disse que o primeiro anel iria se romper no primeiro esforço que eu fizesse. E aí tossi. Se rompeu. Quanto mais tossia, rompia os outros. Eu senti que meu coração parava. Se eu rompesse o quarto, eu não iria existir mais. Houve uma pausa, e comecei a me asfixiar. Eu sentia a morte chegando. Só meu coração batia. Quando eu estava no mundo dos mortos eu cheguei em um castelo dourado, havia uma cruz dourada. Era o paraíso. Quando estava abrindo a porta, ia entrar e não sair mais, ia ficar lá, aí senti que me metiam o dedo na garganta, e aí comecei a reagir, engasgar. Me tiraram no limite de entrar lá. Eu via meu pai e minha avó, todos mortos. Por último vi o laço do meu coração, vi o anel ao redor do coração, e se eu rompesse esse, havia umas mãos segurando o coração. Me diziam: "tens que lutar por este anel". Era só o coração que trabalhava, era o único que se entregava à vontade de trabalhar. Diziam que 
ainda não era a hora de eu ir. Eu via muitas almas, pessoas com asas de anjos que voavam. Via meu pai. Senti que meu pai queria me levar, me faltava a respiração, eu não aguentava mais. Jacques insistia me fazendo respirar. Eu não podia dormir depois, tinha que ver a luz do dia. Se eu dormisse iria passar o resto da vida na escuridão. Passei todo o dia seguinte vendo coisas, via Jesus, via anjos, via Jesus no seu sofrimento, via caixões. Depois da missa isso passou. Voltei para a casa do Jacques, e fiquei vendo televisão. Aí consegui dormir sem ficar vendo coisas, sem acordar toda hora. Depois, quando acordei no dia seguinte, minha mente estava clara, passei a pensar nas coisas que eu havia visto. Os anéis que se romperam foram tempos de vida. Cada vez que tossia rompia uma etapa da minha vida. E eu não queria que rompesse minh a vida. O primeiro era o sofrimento que tive na minha infância. O segundo era passar a um segundo nível. O último era que devia lutar pelo que queria na minha vida.

\section{PURGAS}

É realmente interessante como as purgas (que, em um primeiro momento, podem parecer algo tão sem sentido, por se tratar de uma experiência que nos parece tão desconfortável - vomitar) são tão bem vistas pelos pacientes em Takiwasi. É bastante comum que eles peçam para tomar purgas mesmo não havendo uma sessão específica para isso.

Segundo Fábio"11, paciente em Takiwasi, após uma sessão de purga ele se sente mais limpo:

Posso pensar melhor. A purga é duro, é dificil, mas depois que passa o mal-estar, você fica mais leve. O que penso é que estas ervas limpam, a droga me fez mal, tenho coisas no estômago que não haviam saído, estas ervas tiram as coisas do teu corpo, a droga que está aí e não sairia, ficaria ali a té tua morte. Vai melhorando o figado, os rins. Meus joel hos estavam mal, mas agora estou bem, jogo até futebol.

Fábio teve um acidente de motocross, que lhe deixou marcas no rosto e problemas nas articulações. Mas as purgas não fazem apenas uma limpeza física. $O$ ato de vomitar abre uma conexão com as emoções e lembranças relacionadas ao consumo de drogas. Segundo Fábio:

Com purga de tabaco, na primeira vez, comecei a lembrar de coisas de quando consumia, de que quando deixava de consumir tinh a depressão, pensamentos ruins, todos esses pensamentos voltaram, horríveis, não podia dormir com as lembranças, não podia dormir. A segunda vez foi igual, fiquei nervoso, pensava

11 Entrevistado em 17 de setembro de 2009 , com 38 anos. Natural de Tacna, Peru, administrador de empresas. Tem curso superior incompleto, corre de motocross e tem metade do rosto reconstituído com titânio, devido a um acidente. 
coisas ruins de minha esposa. O tabaco trouxe de volta tudo isso, mas só durante a noite. No dia seguinte estava muito bem. É uma purga que me exige muito mentalmente, me tira tudo, e no dia seguinte estou bem. O tabaco te faz pensar, e pensava coisas ruins, no consumo, e no dia seguinte eu estava liberado de tudo.

Gabriel ${ }^{12}$, um francês com histórico de abuso de heroína, relata uma experiência similar. Para ele "as purgas servem para limpar, para limpar todos os produtos das drogas, e para relaxar a mente". Um outro efeito das purgas normalmente relatado é de reduzir a crise de abstinência. Gabriel relata:

A purga foi muito importante quando cheguei aqui, me ajudou a remover as coisas, e os sintomas da privação não foram tão ruins quanto eu esperava. Foi muito difícil, mas não tanto. Estava mal quando cheguei aqui, com diarreia. Depois da primeira purga vomitei por 48 horas, mas senti que estava me limpando, e depois senti que a planta estava trabalhando para me limpar.

Gabriel diz gostar de tomar purgas de tabaco:

Depois da purga de tabaco me sinto mais energizado, com mais disposição para seguir o tratamento. Me dá coragem para tudo, me ajuda a limpar a mente e reestruturar os temas de forma mais clara. Na primeira purga de tabaco eu senti essa energia, senti que estava removendo coisas de meu passado.

Juca ${ }^{13}$, outro paciente, também relata que as purgas Ihe ajudaram no processo de abstinência. Ele faz um paralelo com um tratamento anterior, em uma outra instituição:

Em Pucalpa havia duas semanas que eu estava internado, e tinha diarreias fortes, líquidas, por abstinência. Por vezes não conseguia chegar ao banheiro. Senti isso por quase um mês. Quando paras de consumir, tens essa diarreia. Aqui as purgas me limparam. Não senti a abstinência, não tive diarreias. As purgas, em um primeiro momento, foram muito fortes. Pouco a pouco, conforme o corpo vai se limpando, não te faz tão mal. As purgas controlam a abstinência. Não senti angústia de consumir, nada.

César ${ }^{14}$, mais um paciente, nos dá um relato mais detalhado sobre o processo de conexão entre purgas e "limpeza":

Em primeiro lugar, quando vou purgar, na maioria das vezes ponho uma intenção. Digo a mim mesmo que quero trabalhar, por exemplo, "por que tenho
12 Entrevistado em 11 de setembro de 2009, com 31 anos. Natural de Paris, França, trabalhou como engenheiro de som durante quatro anos, e com D], tendo concluído o segundo grau. Devido ao uso abusivo de heroína, não pôde mais trabalhar. Tinha 18 anos de consumo de drogas fortes. Usou metadona par tratar o vício em heroína e ficou adicto da metadona.
13 Entrevistado em 14 de setembro de 2009, então aos 34 anos, sendo natural de Moyobamba, Peru. Trabalhou como técnico eletricista e professor primário. Trabalhou também em vendas. Interno desde 31 de março de 2009.

14 Entrevistado em 23 de setembro de 2009, 28 anos. Natural de La Paz, Bolivia. Terminou o secundário e começou administração de empresas, nos Estados Unidos. No entanto, sempre quis fazer teatro, logo largou a administração. De uma família de administradores, engenheiros e políticos, era esperado que César seguisse carreira em uma destas áreas, não teatro. 
tanta cólera?", ou posso averiguar se me ajuda a colocar para fora. Então, quando vomito, às vezes me vem um pensamento, e eu sei onde está o mal humor. $E$ quando não me vem um insight de porque estava assim, nos dias seguintes começo a me dar conta porque estava de mal humor, ou começo a ter problemas no convivio por estar de mal humor, e dentro destes problemas que tenho começo a ver porque estou desta forma. É bem vivencial, querendo ou não, se não vem pela cabeça, pelo coração, pela emoção, sai pelo estômago.

Jorge ${ }^{15}$, terapeuta, dá uma explicação mais clara sobre os processos pelos quais a purga é efetiva:

Casa planta tem um efeito particular e vai trabalhar em um ponto específico de teu corpo e da tua vivência emocional, da tua psicologia, de teu espírito. Mas, em geral, as purgas agem de forma muito rápida, é o que se sente primeiro,é uma limpeza corporal, física: a partir do vômito se pode liberar tensões, toxinas, substâncias, uma série de coisas que estão acumuladas no corpo e que podem, dessa forma, sair. É como uma catarse a partir da liberação de certas substâncias. Quase sempre tem um conteúdo emocional, psicológico. Não é apenas vomitar, mas, se estás tensionado, te relaxa, te equilibra, te dá algo mais, não apenas o vomitar.

Segundo Rosa, o vômito muitas vezes é acompanhado de imagens mentais com forte conteúdo psicológico. Os pacientes podem vomitar ódio, raiva. Ela conta que muitas vezes os pacientes relatam sentir no vômito o cheiro de substâncias ingeridas muito tempo antes da purga, anos até: "logicamente essa substância não estava no corpo, mas há alguma coisa que sai, pode ser energético, ou pode haver um acúmulo. Há uma catarse, uma eliminação pelo corpo de coisas que vão mais além do físico, que são relacionadas ao emocional ou ao espiritual".

Perguntei a Rosa como se dava essa passagem do energético para o físico. Segundo ela,

Na medicina tradicional, são vários corpos, é uma visão mais holística, são várias camadas uma sobre a outra, há o corpo físico, o emocional, o espiritual, o familiar, o social, etc. Então, quando você vomita, não é apenas o corpo físico que está vomitando, mas o emocional está a trelado a este. Em uma cosmovisão amazônica tudo está interagindo. Não existem compartimentos separados. Você está atuando sobre o corpo físico, mas está influenciando os outros também. Isso te mobiliza emoções, conteúdos psicológicos.
15 Entrevistado em o9 de setembro de 2009. 26 anos. Psicólogo, natural de Lima, trabalhava em Takiwasi havia um ano, tendo trabalhado antes um ano como prática para finalizar sua formação. 


\section{DIETAS}

Tiago $^{16}$, terapeuta, diz que a dietas servem para

desintoxicar e para se aprofundar em temas que tenham surgido na ayahuasca ou na psicoterapia. Vocêse confronta com sua solidão, com sua ansiedade, com seus mecanismos, para enfrentar a você mesmo. Muita gente pensa, pensa, pensa, a té que se acaba o pensamento, e quando se acaba esta forma de processar, se confronta com sua ansiedade, com sua sexualidade, suas angústias, seus desejos, seu consumo, sua luminosidade ou obscuridade, se encontra consigo mesmo. Para isso servem as dietas: um encontro carinhoso ou intenso consigo mesmo. Isso gerará sonhos, tomadas de consciência, pensar, reflexionar sobre você mesmo.

Segundo Rosa, tradicionalmente as dietas têm dois objetivos: cura ou aprendizagem:

Cura e aprendizagem são os dois lados da mesma moeda. A grande parte dos curandeiros são curandeiros por que caíram doentes e, no curso da enfermidade, começaram a tomar plantas para se curar e tiveram o convite para serem curandeiros, e curandeiros de coisas muito precisas, como curar crianças, velhos.

Para Rosa a diferença entre o uso da ayahuasca e a dieta é que

a dieta permite mudanças estruturais fortes na pessoa. Enquanto a ayahuasca é muito pessoal, muito interessante ao nivel racional por ter a imagem, a história, digamos assim, a dieta é muito mais importante porque mobiliza toda a energia do corpo. É um espaço em que há uma espécie de intercâmbio. É como zeraro relógio biológico, porque se come apenas o básico, o corpo se desintoxica, até o ponto em que muitas vezes, das pessoas que estão no segundo, terceiro dia de dieta, os bichos se aproximam, as mariposas, o suor, de amargo ou salgado, passa a ser sem gosto. A dieta é um trabalho com mais profundidade. A ayahuasca é um cipó, e assim sendo, dá um suporte. A dieta se faz sem esse suporte, se constrói este suporte.

Em relação à aprendizagem e à aquisição de conhecimentos de cura ou xamânicos, a dieta por vezes é uma exigência das próprias plantas. Por exemplo, Rosa contou que, certa vez, ela estava cuidando de uma dieta de Jacques (ela mesma ainda não havia feito nenhuma dieta):
16 Entrevistado em 22 de setembro de 2009, então aos 34 anos. Natural de Lima Peru, também é psicólogo. Trabalhava há 12 anos, sete dos quais em Takiwasi. 
Estava cozinhando plantas. Estive cozinhando, por todo o dia, uma preparação com 40 plantas diferentes. Estava muito cansada e dormi ao lado da panela de plantas, e naquela noite sonhei que de todas as árvores se abriam os troncos e que havia dentro delas pequenas pessoas que saíam de noite, que vinham caminhando e conversando entre elas. Eu estava muito mareada, e não sabia se era sonho ou uma visão. Eu vi no sonho todas as plantas que havia no preparado. Cada uma vinha perto de mim e dizia: "eu curo tal coisa". Eu escutava o que me diziam, mas escutava mal. Não vocalizavam bem, escutava as palavras pela metade, e me parecia que era algo muito interessante, muito importante, estava entre desperta e adormecida, meio visionária, e me dava raiva não entender o que diziam. Elas vinham, bailavam, faziam coisas e se apresentavam, diziam: "eu me chamo tal planta, e sirvo para curar isto e aquilo", e me ensinavam como prepará-las, como cortar. Eu via que vinha uma fila de pessoas feridas, como que em uma guerra, com dores, doentes, e que cada um dizia: "esta é para mim!", e cada um fazia seu preparado. Mas, em alguns momentos estava tudo ordenado, mas em outros era um caos, vários falavam ao mesmo tempo, minha atenção estava muito difusa, e perdia a qualidade, eu não podia centrar minha atenção. Isso me desesperava, porque sentia que era algo interessante. Apesar de estar em um estado de sonho, meio desperta, meio adormecida, eu era consciente que era uma aprendizagem importante. Em alguns momentos eu dizia: "silêncio, não posso me concentrar!", e eles me diziam: "se você aprender, tens que fazer uma dieta".

Cada planta de dieta atua em um nível diferente - ainda que seus efeitos possam variar de pessoa para pessoa. Segundo Jean (paciente em Takiwasi):

os efeitos de cada planta são muito distintos. Com ushpawasha [Rauwolfía s.] todos os sentimentos do meu passado voltaram, chorei muito, tive cólera, medo, sentimentos distintos de meu passado, foi muito forte no meu corpo. Com palos (uma combinação em água da casca de diversas árvores), na segunda vez, eu senti que meus antebraços estavam duros, minha cabeça, minhas pernas estavam pesadas. Com a mucura [Petiveria alliacea - conhecida no Brasil como guiné] eu senti diretamente, de maneira muito rápida estava muito "na minha cabeça", com muitos pensamentos, entendi muitas coisas, isso foi muito forte. $\mathrm{Na}$ terceira vez, com ajo sacha [Mansoa stendlyi], não senti muito o efeito, eu tomava a planta, e ficava esperando o efeito, que ela fizesse o trabalho dela. Depois de dois dias comecei a me perguntar porque não sentia o efeito da planta. Contei tudo ao meu terapeuta, que disse que isso era normal, e que a planta trabal hava inconscientemente, e que depois da dieta as coisas viriam pouco a pouco. Disse também que eu devia trabal har nos meus assuntos, e não ficar apenas esperando que a planta fizesse o trabalho. 
Duas outras plantas de dieta têm seus efeitos bastante pronunciados. Uma delas é o chiric sanango (Brunfelsia grandiflora), uma solanácea. O chiric é utilizado para "tirar o medo", uma planta que causa uma sensação de frio intenso. A outra é o ucho sanango (Bonafousia undulata), que provoca uma sensação de calor intenso, e é tida como responsável por "queimar" demônios e outras energias negativas.

César teve uma experiência muito intensa com ucho:

Foi forte. Na primeira vez não consegui reter o uchu. Me "picava", saia por meu nariz e picava meus olhos. Dentro de minha barriga parecia que algo espremia minhas tripas, me queimava. Na segunda vez, quando me levaram ao rio para me banhar, parecia que havia um trator passando por cima de meu corpo, esmagando meus ossos. Não podia enxergar direito. Me recordo que tinha calor. Não podia pensar coerentemente. A dieta passou muito rapidamente. O uchu me ajudou a queimar cargas que tenho desde minha infância e experiências com alucinógenos, energias muito carregadas. Mas como não podia pensar em nada, me vinham inspirações sobre meu processo, no que eu estava trabalhando, enos sonhos sonhava com meu pai, minha mãe, irmãos, vinha tudo em sonhos. Quando me dei conta que estava sonhando muito, fazia perguntas antes de dormir, como por exemplo: "gostaria de saber porque me comportava assim com meu irmão". E me vinha a resposta em sonho.

Lucas $^{17}$, um dos terapeutas, teve também uma experiência extremamente forte com uchu:

Para mim a dieta é efetiva em si mesma. Fiz duas dietas, com ushpa e uchu. As duas muito bonitas, mas a de uchu foi a experiência mais forte que já tive na minha vida. O uchu é como tomar um concentrado de pimenta que te queima tudo, por cima e por baixo. É a planta mais masculina de todas, é o "macho" das plantas. O grande curandeiro, que tem a ver com a força, com a vontade, $e$ também com a habilidade de queimar, purificar tudo. Minha dieta de uchu foi super importante para o trabalho que faço aqui, pelos conteúdos que eu estava trabalhando nas sessões de ayahuasca, certos temas pessoais, em relação à minha família. Foi bastante forte, como se tivessem abrindo o peito e saísse fogo de dentro. Neste momento, eu só vivia as sensações físicas, mais tarde a parte psicológica ficou mais evidente. Durante a parte mais intensa, eu tinha algumas intuições, mas não podia me focar nelas. Depois comecei a escrever, a desenhar. Tive sonhos muito interessantes, a sonhar com as plantas, coisas assim bem dramáticas e explícitas. Aí meu ceticismo foi deixado de lado. Em um sonho uma planta te aparece e te diz frase terapêuticas, certeiras.
17 Entrevistado em 15 de setembro de 2009. Natural de Santiago, Chile, tinha à época 27 anos. Estava no Peru havia um ano e meio. Psicólogo formado desde 2005, já havia trabalhado na Argentina, e no Chile. 


\section{PSICOATIVOS, AGÊNCIA, LÍNGUA E LINGUAGEM}

Marras argumenta que os efeitos das substâncias psicoativas não estariam na "substância em si", nem na "sociedade", mas na agência de uma sobre a outra, na rede entre ambas. Seguindo o argumento de Marras, nossa sociedade veria nas experiências com psicoativos um "excesso de subjetivação" (2008: 175), excesso esse que colocaria em risco a existência mesma da vida em sociedade, tida como a contraparte objetiva desta existência.

Para os seguidores das religiões brasileiras que utilizam a ayahuasca em seus rituais esta substância

facilita o acesso a mundo espiritual, tanto por ser ela mesma um "ser divino", um espírito encarnado na forma de uma bebida santa, quanto por ser um agente químico, alterador das funções cerebrais e corporais. Forma-se assim uma lemniscata, o símbolo do infinito, exatamente porque início e fim se confundem, se tocam. Espírito e matéria se tornam unos e se influenciam mutuamente (Mercante 2012: 22).

A ayahuasca, no universo indígena, também é considerada um espírito poderoso "por meio do qual poder e conhecimento podem ser adquiridos" (Luna, 1986: 60). Luna classifica a ayahuasca como uma "planta professora", exatamente porque este "espírito" revela o conhecimento contido em outras plantas e animais, em lugares e pessoas. O espírito da ayahuasca é responsável por efetivar o contato com os espíritos de outros seres e coisas, outros não-humanos. O espírito da ayahuasca é também, na concepção de Luna, um "doutor", um "médico". A ayahuasca possui uma linguagem própria, assim como a capacidade de traduzir a linguagem de outras plantas ou espíritos, e facilitar a comunicação destes com os seres humanos.

Existem, no entanto, outras plantas professoras, como ficou evidente nos vários relatos acima. Tais ensinamentos vêm por meio de uma linguagem peculiar, elaborada em visões e sonhos ou então por meio de modificações mais físicas, como vômitos e catarses, proporcionando entendimentos e compreensões. Todas estas plantas constroem uma narrativa sobre a qual se desenvolve o tratamento.

Benjamin, em um texto de 1916, faz uma busca pela essência da linguagem, não apenas nos seres humanos, mas no universo em geral. Tanto humanos quanto não-humanos seriam dotados de linguagem, ainda que somente os humanos fossem dotados da capacidade de expressão através da palavra, o que Ihes daria uma vantagem comunicativa. Todas as coisas, animadas e inanimadas, participam da linguagem, segundo Benjamin, pois comunicar seu conteúdo 
espiritual é "essencial a tudo" (2011: 51), ainda que tenhamos diferentes graus de consciência quanto à apreensão do conteúdo expresso em qualquer comunicação. Assim, várias facetas de uma coisa podem ser reveladas, na medida em que essa coisa se comunica com os humanos.

Para Benjamin, a diferença entre a linguagem humana e a linguagem das coisas se baseia no fato de que "toda natureza, desde que se comunica, se comunica na língua, portanto, em última instância, no homem". Um espírito é tão exprimível quanto mais real e existente ele for, e o que "mais se exprime, é ao mesmo tempo o espiritual em sua forma mais pura" (2011: 56/59).

Ele continua então, explorando mais profundamente a diferença entre linguagem humana e linguagem das coisas. Segundo o autor, as coisas exprimem a linguagem de forma imperfeita, pois a língua dos objetos é imperfeita, uma vez que eles são mudos, pois "às coisas é negado o puro princípio formal da linguagem que é o som" (Benjamin, 2011: 60). O som (humano) produzido na interação entre o espírito das plantas e as pessoas que as ingeriram se manifesta de várias formas: através de ícaros que são ensinados pelos espíritos às pessoas, para que elas cantem e os invoquem; através da palavra dos pacientes nas sessões de psicoterapia, quando relatam aos psicoterapeutas suas experiências e o que elas significaram para seu processo de tratamento.

É exatamente dessa expressão sonora que surge o conhecimento:

Traduzir a linguagem das coisas para a linguagem do homem não consiste apenas em traduzir o que é mudo para o que é sonoro, mas em traduzir aquilo que não tem nome em nome. Trata-se, portanto, da tradução de uma língua imperfeita para uma língua mais perfeita, e ela não pode deixar de acrescentar algo, 0 conhecimento (Benjamin, 2011: 64-65).

No caso do tratamento, este é o conhecimento das causas que levaram (ou levam) os pacientes ao uso de drogas, à dependência, assim como o conhecimento das consequências do uso abusivo destas substâncias. Os curandeiros e terapeutas aprendem com estes espíritos, invocam-nos durante os rituais para auxiliá-los. Mas este mesmo processo se dá com os pacientes. Neste ponto, muitas vezes os curandeiros e terapeutas auxiliam os pacientes na compreensão do que está sendo dito pelos espíritos das plantas. Todos adquirem conhecimento com os espíritos, tal conhecimento é fruto de um processo de interação e surge nas falas e narrativas de terapeutas e pacientes, assim como nas canções rituais.

Viveiros de Castro utiliza a ideia de que os espíritos seriam os "não-humanos invisíveis", ainda que haja problemas com essa definição, pois tais "não-humanos" se apresentam muitas vezes como humanos, tanto na sua forma corporal quanto na sua capacidade de agência e intenções. A solução desse dilema, para 
este autor, é uma questão de perspectiva: "enquanto (normalmente) invisíveis, esses não-humanos 'são' humanos; enquanto (anormalmente) visíveis, esses humanos 'são' não-humanos" (2006: 325).

O pêndulo entre visibilidade e invisibilidade nos remete à questão da imagem. Que fique claro que "imagem" não se refere apenas ao que podemos "ver". Imagem está, neste contexto, relacionada a todo campo perceptivo-temos imagens auditivas, táteis, olfativas, assim como imagens emocionais. Viveiros de Castro defende que uma imagem é "algo-para-ser-visto, é o correlativo objetivo necessário de um olhar, uma exterioridade que se põe como alvo da mirada intencional" (2006: 325). Eu iria mais longe: imagens são para serem sentidas. Tais imagens são internas, são experienciadas durante o transe causado pelo uso ritual de psicoativos, elas não são acessíveis a qualquer pessoa, em qualquer lugar.

Temos aqui, então, imagens dos espíritos e imagens pessoais, causadas pela interação com tais espíritos. Viveiros de Castro ainda sugere que os espíritos seriam

imagens que seriam então como a condição daquilo de que são imagem; imagens ativas, índices que nos interpretam antes que os interpretemos; enigmáticas imagens que devem nos ver para que possamos vê-las (...) imagens através das quais vemos outras imagens (...). Tal não-iconicidade e não-visibilidade empíricas, em suma, parecem apontar para uma dimensão importante dos espíritos: eles são imagens não-representacionais, representantes que não são representações (ênfases originais, 2006: 325).

As imagens, portanto, são a linguagem dos espíritos.

Esta relação entre espíritos e imagens se torna tão intensa que ambos se confundem. Os espíritos passam a ser as imagens, o que, para Viveiros de Castro, é um tipo de relacionamento entre humanos e não-humanos, relacionamento este fundamentado sobre uma experiência, um "fundo universal imanente (...) que vem à tona (...) no sonho e na alucinação, quando o humano e o não-humano, o visível e o invisível trocam de lugar" (2006: 326). Espíritos são, assim, "nomes de relações, experiências, movimentos e eventos (...) eles seriam dispositivos de imaginação" (ênfases originais, 2006: 327). O curandeiro une, através da imaginação, o som e a imagem, o nome e a visão. Ele nomeia - e nomeia porque recebe esse nome dos espíritos que vê, e ao nomear, ele canta. Ao cantar, ele induz outras pessoas a verem o que ele vê, e assim ele traduz o conhecimento que adquire das imagens e das coisas - um conhecimento que tem origem na tradução da linguagem das plantas para a linguagem humana. Viveiros de Castro, assim, completa o roteiro que Benjamin havia iniciado.

Os espíritos habitariam, deste modo, um "espaço espiritual" (Mercante, 2012) 
e o contato com eles se daria, muitas vezes (mas não exclusivamente), durante os rituais. Os rituais interconectam imaginação e consciência. A imaginação é uma linguagem,

uma atividade, um jogo com diversas imagens mentais, jogo que envolve não apenas criar novas imagens, mas conscientizar-se quanto às vel has e com elas trabalhar, tentando lhes conferir novas formas e significados. Essa é a forma como é feita a transição entre um plano inefável, em tese intangivel (e que pela imaginação ganha forma, peso, consistência e possibilidade de ser manipulado), e o mundo físico. Ao tocar o mundo físico, a imaginação começa, então, a transmutá-lo. As funções cerebrais são profundamente afetadas, e, consequentemente, todo o corpo. Esse é o momento da cura, da transformação, da liberação, da descoberta (Mercante 2012: 22).

\section{CONCLUSÃo}

As coisas possuem voz. O curandeiro é responsável por comunicar essa voz. Ele canta e invoca essas vozes durante o ritual, através dos ícaros. Ao invocar os nomes das plantas, o curandeiro invoca sua essência espiritual, que age sobre a consciência dos pacientes durante o ritual, cada qual com sua agência específica. Os resultados dessa agência são subjetivos, não por uma estrutura frouxa da essência espiritual das plantas, mas pela variedade de histórias de vida dos pacientes. Este é o caminho pelo qual, em Takiwasi, trata-se a dependência: através do espírito da ayahuasca e das outras plantas.

As plantas são entendidas como seres espirituais, portadoras de uma linguagem e de agência. Tal linguagem é apreendida por curandeiros e terapeutas, e aplicada no âmbito do ritual e do tratamento. Isto acontece, como pudemos ver através das narrativas apresentadas ao longo do texto, ao se colocar em contato com os espíritos das plantas, mas principalmente das plantas professoras.

Os pacientes são os recipientes finais deste processo. Abra-se, por meio do espírito das plantas na imaginação dos pacientes, um espaço de tratamento através de experiências bastante físicas, mas que alcançam todos os níveis de existência. A imaginação potencializada pela linguagem do espírito das plantas atua no corpo e a partir do corpo: finda a dualidade, somente o espírito/corpo permanece. $O$ espírito/corpo e a linguagem.

O processo de comunicação entre o espírito das plantas e os pacientes acontece durante as experiências relatadas acima. Durante uma dieta com uchu sanango não se "queimam" os conteúdos emocionais ou os demônios devido à ação dos princípios ativos (químicos) desta planta. Mas sim porque o uchu, como disse Lucas, é uma planta masculina, é o "grande curandeiro", que trabalha com a vontade do pa- 
ciente. É o espírito da planta que comunica ao paciente sua linguagem específica e, no processo de interação entre ambos - paciente e planta-, acontecem seus efeitos.

É exatamente porque o resultado final depende desta interação que os efeitos destas plantas - ou de seus espíritos - é tão variado: tudo vai depender da comunicação que se estabelece, de como a mensagem é transmitida, escutada e finalmente compreendida. Por isso é tão complicado (em minha opinião, impossível) traçar uma rota linear entre causa e efeito, química e experiência.

Os espíritos das plantas nomeiam, ou seja, tornariam conscientes emoções, sentimentos e sensações pertencentes ao paciente. Ao nomear estes "espíritos" que o próprio paciente carregava dentro de si-mas com os quais não conseguia ou não desejava manter um processo de comunicação, de relação-, o paciente os escuta, abrindo-se então uma via para que possa compreendê-los. Ao compreendê-los, o paciente teria então a possibilidade de transformá-los. Sendo assim, é o espírito da planta que revela ao paciente seus "demônios" internos, é o espírito da planta que nomeia tais espíritos. Nomear é um ato "divino", segundo Benjamin. Os seres humanos, continuando com Benjamin, partindo de uma visão bíblica, seriam os únicos, além de Deus, a nomear as coisas, e isso ocorreria porque os seres humanos seriam capazes de se comunicar com tais coisas. Mas aqui vemos que tal comunicação pode ser mais ampla, e partir das próprias plantas. O ritual Ihes confere voz e agência.

Marcelo S. Mercante é antropólogo, atuando na área de religiosidade, espiritualidade e saúde. Vem realizando pesquisas envolvendo a ayahuasca desde 2001. Autor de Imagens de Cura: ayahuasca, imaginação, saúde e doença na Barquinha (Ed. Fiocruz).

\section{REFERÊNCIAS BIBLIOGRÁFICAS}

BENJAMIN, W.

2011 "Sobre a linguagem em geral e sobre a linguagem do homem". In GACNEBIN, Jeanne Marie (org.). Escritos sobre mito e linguagem. São Paulo, Editora 34, pp. 49-74.

\section{BUSTOS, Susana}

2008 The Healing Power of the Icaros: A Phenomenological Study of Ayahuasca Experiences. São Francisco, tese de doutorado, California Institute of Integral Studies. 
GIOVE, Rosa

2000 La liana de los muertos al rescate de la vida. Medicina tradicional amazónica en el tratamiento de las toxicomanias. Siete anõs de experiencia del Centro Takiwasi. Tarapoto, Takiwasi.

HARRINGTON, Nora

2008 The Psychology of Plants. An Ethnography of Patient-Provider Relationship at the Takiwasi Center for Rehabilitation. Amherst, dissertação de mestrado, School of Social Sciences, Hampshire College.

HUXLEY, Aldous

1990 The Doors of Perception and Heaven and Hell. Nova York, Harper \& Row.

LABATE, Beatriz C. e ARAÚjO Wladimir S.

2002 O uso ritual da ayahuasca. Campinas, Mercado das Letras.

LABATE, Beatriz C. e COULART, Sandra

2005 O uso ritual das plantas de poder. Campinas, Mercado das Letras.

LANCDON, Esther Jean

1996 Xamanismo no Brasil: novas perspectivas. Florianópolis, Edufsc.

LUNA, Luis E.

1986 Vegetalismo: Shamanism among the Mestizo Population of the Peruvian Amazon. Estocolmo, Almqvist \& Wiksell International.

MABIT, Jacques

2002 "Blending Traditions: Using Indigenous Medical Knowledge to Treat Drug Addiction". Maps Bulletin, vol. 12, n. 2: 25-32.

2007 "Ayahuasca in the Treatment of Addictions". In WINKELMAN, Michael e ROBERTS, Tom B. (orgs.). Psychedelic Medicine. New Evidence for Hallucinogenic Substances as Treatments, Volume 2. Westport, Praeger Perspectives, pp. 87-106.

MABIT, Jacques; GIOVE Rosa e VEGA, Jose

1996 "Takiwasi: The Use of Amazonian Shamanism to Rehabilitate Drug Addicts". In WINKELMAN, Michael e ANDRITZIKY, Walter (orgs.). Yearbook of Cross-Cultural Medicine and Psychotherapy 1995. Theme Issue: Sacred Plants, Consciousness, and Healing. Cross-Cultural and Interdisciplinary Perspectives. Berlim, Verlag für Wissenschaft und Bildung, pp. 257-285. 
MARRAS, Stelio

2008 "Do natural ao social: as substâncias em meio estável", In LABATE, Beatriz; COULART, Sandra; FIORE, Maurício; MACRAE, Edward e CARNEIRO Henrique (orgs.). Drogase cultura: novas perspectivas. Salvador, Edufba, pp. 155-186.

MERCANTE, Marcelo S.

2010 Images of Healing: Spontaneous Mental Imagery and Healing Process of the Barquinha, a Brazilian Ayahuasca Religious System. Saarbrücken, Lambert Academic Publishing House.

2012 Imagens de cura. Ayahuasca, imaginação, saúde e doença na Barquinha. Rio de Janeiro, Editora Fiocruz.

2013 "A ayahuasca e o tratamento da dependência". Mana, vol 19, n. 3: 529-558.

NARBY, Jeremy e Huxley, Francis

2004 Shamans Through Time. 500 Years on the Path to Knowledge. Nova York, Penguin Books.

SAEZ, Oscar C.

2014 Teorias, actores y redes de la ayahuasca. Ilha vol. 16, no.1: 7-40.

SALDAÑA, Álvaro C. e GUIRRIMÁN, Mônica O.

2008 Aproximaciones antropológicas al modelo terapéutico del Centro Takiwasi. Tarapoto, dissertação de mestrado, Universidad Católica de Temuco.

SHANON, Benny

2002 The Antipodes of the Mind: Charting the Phenomenology of the Ayahyuasca Experience. Cambridge, Oxford University Press.

VIVEIROS DE CASTRO, Eduardo

2006 "A floresta de cristal: notas sobre a ontologia dos espíritos amazônicos". Cadernos de Campo, vol. 14/15: 319-338. 


\section{ABSTRACT}

In this paper I analyze the role of the plants used in the treatment of chemical dependency in a treatment center, Takiwasi, located in the Peruvian Amazon. Ayahuasca is a central tool in the recovery process in Takiwasi. Ayahuasca is a psychoactive drink widely used by many indigenous populations across the Amazon and by three Christian-based Brazilian religions. Plants are believed to be endowed with agency in Takiwasi, and have, in addition to its active chemical principles, another type of action: the spiritual, seen as more effective than the chemical action. To elucidate such capability of agency and spiritual power, I use Benjamin's ideas of "language" and "spirit", and also Viveiros de Castro's "image" and "imagination".

Recebido em 11 de abril de 2016. Aceito em 17 de março de 2017.

\section{KEYWORDS}

Ayahuasca, Addiction, Spontaneous Mental Images, Agency 